\title{
Crescimento radicular e produção de ácidos orgânicos em cultivares de soja com diferentes tolerâncias ao alumínio(1)
}

\author{
Orival Gastão Menosso(2), José Antonio Costa(3), Ibanor Anghinoni ${ }^{(3)}$ e Humberto Bohnen ${ }^{(3)}$
}

Resumo - A elucidação dos mecanismos que definem o comportamento diferencial entre genótipos de soja quanto à toxidez de $\mathrm{Al}$ facilita a utilização da variabilidade genética existente ou produzida. $\mathrm{O}$ objetivo deste trabalho foi avaliar a influência do $\mathrm{Al}$ no crescimento radicular, na modificação do $\mathrm{pH}$ da solução e no conteúdo de ácidos orgânicos em extratos de raízes de cultivares de soja tolerantes ao Al, FT-1 e FT-6 (Veneza) e sensíveis, IAC-13 e Paraná. As plantas cresceram por nove dias em solução contendo $50 \mathrm{mg} \mathrm{L}^{-1}$ de Ca e 0,0 e $0,2 \mathrm{mg} \mathrm{L}^{-1}$ de Al, com pH inicial de 4,76. Houve maior crescimento de raízes nas cultivares tolerantes e não houve alterações do $\mathrm{pH}$ da solução relacionadas à tolerância das cultivares ao alumínio. A presença do Al reduziu o conteúdo dos ácidos cítrico, lático, succínico, oxálico e málico, em ambos os grupos de cultivares avaliados, porém com maior redução no grupo das cultivares sensíveis. O ácido cítrico foi encontrado em maior quantidade nas cultivares tolerantes. A capacidade das cultivares de soja FT-1 e FT-6 (Veneza) de alterar o conteúdo de ácidos orgânicos não-voláteis, principalmente o ácido cítrico, que pode complexar o $\mathrm{Al}$, indica que este mecanismo pode ser muito importante para a tolerância a esse elemento.

Termos para indexação: Glycine max, pH, ácido cítrico, raízes, extratos.

\section{Root growth and production of organic acids by soybean cultivars with different tolerance to aluminum}

\begin{abstract}
The understanding of the mechanisms for the differential performance of soybean genotypes in relation to $\mathrm{Al}$ toxicity is important to explore the existing or produced genetic variability. The objective of this study was to determine the $\mathrm{Al}$ influence on root growth, solution $\mathrm{pH}$ modifications and organic acid content in root extracts of Al tolerant, FT-1 and FT-6 (Veneza) and sensitive, IAC-13 and Paraná, soybean cultivars. Plants were grown during nine days in a solution containing $50 \mathrm{mg} \mathrm{L}^{-1}$ of calcium and 0.0 and $0.2 \mathrm{mg} \mathrm{L}^{-1}$ of aluminum. The solution $\mathrm{pH}$ at the beginning was 4.76 . Root growth in $\mathrm{Al}$ solutions of the tolerant soybean cultivars was higher than that of the sensitive ones. There was no solution $\mathrm{pH}$ modification related to the tolerance of soybean cultivars to aluminum. The content of citric, lactic, succinic, oxalic and malic acids was reduced in all cultivars in the presence of aluminum. The highest reduction was observed in the Al sensitive cultivars. The largest amount of citric acid was found in the tolerant cultivars. Tolerance of soybean cultivars can be expressed by the content of nonvolatile organic acids, particularly of the citric acid. These characteristics, expressed by the FT-1 and FT-6 (Veneza), suggest that it can be a very important mechanism for Al tolerance in soybean.
\end{abstract}

Index terms: Glycine max, $\mathrm{pH}$, citric acid, roots, extracts.

(1) Aceito para publicação em 12 de dezembro de 2000.

Extraído da Tese de Doutorado apresentada pelo primeiro autor à Universidade Federal do Rio Grande do Sul (UFRGS), Faculdade de Agronomia, Porto Alegre, RS.

${ }^{(2)}$ Embrapa-Centro Nacional de Pesquisa de Soja, Caixa Postal 231, CEP 86001-970 Londrina, PR. E-mail: menosso@enpso.embrapa.br

(3)UFRGS, Faculdade de Agronomia, Caixa Postal 776, CEP 90001-970 Porto Alegre, RS. E-mail: jac@vortex.ufrgs.br ibanghi@vortex.ufrgs.br, bohnen@conex.com.br

\section{Introdução}

A variabilidade genética detectada entre genótipos de soja para tolerância ao alumínio (Al) sugere a possibilidade de ganhos genéticos mediante seu melhoramento. A utilização dessa característica que confere adaptação a certos ambientes adversos do solo pode representar aumentos na produtividade de grãos nos genótipos portadores do caráter, quando 
comparados àqueles que não apresentam essa característica. A compreensão dos mecanismos que identificam o comportamento diferencial entre os genótipos facilita a exploração da variabilidade genética existente ou produzida.

Os mecanismos de tolerância ao Al estão representados por duas classes distintas. A primeira é a inativação do $\mathrm{Al}$ fora da planta (exclusão). Para isso, é necessário que o $\mathrm{pH}$ da solução ao redor da superfície das raízes seja maior do que 5,0, precipitando, assim, o Al e ligando-o aos grupos carboxílicos da parede celular, antes que atinja o plasmalema (Matsumoto et al., 1976), ou que as raízes exsudem quelatos orgânicos (Foy, 1988; Taylor, 1988; Kochian, 1995). Para chegar a valores de $\mathrm{pH}$ mais altos do que 5,0, no apoplasto da raiz, a planta precisa acumular mais ânions do que cátions no citoplasma, para, então, poder excretar ânions

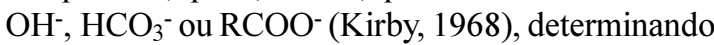
mudanças na solubilidade do $\mathrm{Al}$ e outros elementos. Entretanto, quando há o acúmulo de cátions, ocorre a acidificação da solução.

A segunda classe de mecanismos de tolerância ao Al é sua neutralização dentro da planta. $\mathrm{O} A 1$ pode ser complexado por ácidos orgânicos (Foy, 1988; Taylor, 1988; Kochian, 1995) e mantido inativo no citoplasma (Taylor, 1988), nos vacúolos (Helyar, 1987; Taylor, 1988) ou nas interações com calmodulina (Suhayda \& Haug, 1985), prevenindo os seus efeitos negativos nos processos metabólicos.

Entre os mecanismos propostos para a tolerância ao $\mathrm{Al}$, a capacidade das raízes de produzir diferentes ácidos orgânicos alifáticos, di e tricarboxílicos, tem sido apontada, ultimamente, como a mais importante. Esses ácidos bloqueiam a ação fitotóxica do $\mathrm{Al}$, com a formação de quelatos, especialmente com o ácido cítrico, ao mesmo tempo que mantém uma adequada disponibilidade de P (Klimashevskii \& Chernysheva, 1980; Cambraia et al., 1983; Lee \& Foy, 1986; Miyasaka et al., 1991; Miyasawa et al., 1992).

A determinação da complexação iônica pelos métodos analíticos tradicionais é de difícil interpretação, e geralmente não distinguem o Al livre das outras espécies ligadas com ânions inorgânicos e orgânicos (Miyasawa et al., 1992), e os ensaios com níveis de $\mathrm{Al}$ e ácidos orgânicos têm sido uma das soluções indiretas para esse problema. No entanto, no interior da célula, o índice de $\mathrm{pH}$, na maioria das espécies vegetais, se aproxima da neutralidade: 6,8 a 7,9 (Kurkdjian \& Guern, 1989), o que sugere que o Al é precipitado como hidróxido ou fosfato ou é complexado por grupos orgânicos. Portanto, é difícil visualizar algum movimento do Al dentro da célula que não seja complexado na forma solúvel (Foy, 1988). A capacidade de complexação dos ácidos está relacionada com a posição dos grupos $\mathrm{OH} / \mathrm{COOH}$ da principal cadeia carbônica da molécula. Os ácidos mais eficientes para a complexação e desintoxicação do Al são o cítrico, o tartárico, o oxálico e o málico; no grupo de eficiência moderada, destacam-se o malônico e o salicílico e, no grupo baixa eficiência, o succínico, o lático e o fórmico (Huang \& Violante, 1986; Hue et al., 1986; Miyasaka et al., 1991; Miyasawa et al., 1992; Delhaize et al., 1993).

Os objetivos deste trabalho foram avaliar o efeito do Al no crescimento da raiz primária, nas modificações no $\mathrm{pH}$ da solução e no conteúdo de ácidos orgânicos em extratos de raízes de cultivares de soja, tolerantes e sensíveis ao alumínio.

\section{Material e Métodos}

O experimento foi conduzido em solução nutritiva em casa de vegetação do Departamento de Solos da Universidade Federal do Rio Grande do Sul, Porto Alegre, RS. Envolveu o crescimento de quatro cultivares de soja (Glycine max (L) Merr.) em duas concentrações de Al em solução nutritiva, em recipientes de plástico, azul escuro, de $9 \mathrm{~L}$ e três repetições, com um total de 24 vasos. $\mathrm{Na}$ solução, foi adicionado somente o $\mathrm{Ca}$, como $\mathrm{CaCl}_{2} \cdot \mathrm{H}_{2} \mathrm{O}$, em baixa concentração $\left(50 \mathrm{mg} \mathrm{L}^{-1}\right)$, utilizando-se as concentrações de 0 e $0,2 \mathrm{mg} \mathrm{L}^{-1}$ de Al, adicionado como $\mathrm{Al}_{2} \mathrm{SO}_{4} \cdot 18 \mathrm{H}_{2} \mathrm{O}$. A ausência dos outros nutrientes na solução decorre da grande precipitação do $\mathrm{Al}$ na presença de P (Munns, 1965), e de que as necessidades dos mesmos, em ensaios de curta duração, são supridas pelos cotilédones (McAlister \& Krober, 1951). Foram utilizadas as cultivares de soja, identificadas por Menosso et al. (2000), como sensíveis (Paraná e IAC-13) e tolerantes (FT-1 e FT-6 = Veneza) ao Al, em ensaios de curta duração em solução nutritiva diluída, constituída de $50 \mathrm{mg} \mathrm{L}^{-1}$ de Ca e $0,2 \mathrm{mg} \mathrm{L}^{-1}$ de alumínio. O pH da solução foi ajustado inicialmente em $4,76 \pm 0,03$, e o experimento foi conduzido em blocos casualizados, em esquema fatorial, combinando as quatro cultivares, com dois níveis de $\mathrm{Al}$ e três repetições. 
As sementes das cultivares utilizadas foram uniformizadas quanto ao tamanho e colocadas para germinar em cartuchos de papel em recipiente com água destilada, em câmara de germinação na temperatura de $25^{\circ} \mathrm{C}$. No quinto dia, quinze plântulas uniformes de cada cultivar foram transferidas para cada recipiente, onde foram fixadas em tampa de isopor com $2 \mathrm{~cm}$ de espessura, com furos de $1,9 \mathrm{~cm}$ de diâmetro, sustentadas por um cilindro do mesmo isopor com diâmetro do furo. Os recipientes foram, então, transferidos para casa de vegetação, onde permaneceram por nove dias. $\mathrm{O}$ arejamento da solução foi feito por borbulhamento de ar, de modo contínuo, e o pH, medido diariamente. Foram efetuadas medidas do comprimento da raiz primária das plântulas no dia do transplante e no dia da colheita, para a avaliação do incremento de crescimento radicular. Na colheita, as raízes foram separadas da parte aérea, lavadas com água deionizada, acondicionadas em sacos de plástico, congeladas e armazenadas até a realização das análises.

Para as determinações de ácidos orgânicos alifáticos não-voláteis foram utilizados $2,10 \mathrm{~g}$ de tecido vegetal fresco (armazenado) das raízes de cada cultivar. A maceração de cada amostra foi feita em um gral e pistilo de porcelana, em $10 \mathrm{~mL}$ de etanol a $80 \%$ e mais $10 \mathrm{~mL}$ para a limpeza, durante 15 minutos, à temperatura ambiente do laboratório. As amostras trituradas foram guardadas em tubos de ensaio na geladeira, a $5^{\circ} \mathrm{C}$, por 24 horas (Cambraia et al., 1983). O extrato foi removido do material macerado, por centrifugação a $20.000 \mathrm{~g}$, durante 15 minutos, em duas extrações consecutivas. Do extrato obtido, foram removidos os pigmentos e os lipídios, mediante três extrações, em funil de separação tipo pêra, usando-se $10 \mathrm{~mL}$ de clorofórmio e separando-se a fase aquosa. Os extratos foram evaporados a vácuo, a $70^{\circ} \mathrm{C}$, durante 30 minutos e, posteriormente, a amostra foi diluída em $10 \mathrm{~mL}$ de etanol a $80 \%$ e armazenada em geladeira, a $5^{\circ} \mathrm{C}$, até a análise (Newmann, 1964). As análises dos conteúdos de ácidos orgânicos foram realizadas com um cromatógrafo de fase líquida (HPLC), com sistema de dupla bomba, e um detector ultra violeta com lâmpada de zinco a $212 \mathrm{~nm}$. A coluna analítica foi um polímero de octadecilsilano. As condições de operação consistiram de $\mathrm{H}_{3} \mathrm{PO}_{4} 0,01 \mathrm{~N}$, na fase móvel, a

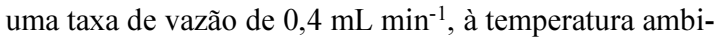
ente e 18 atmosferas de pressão. Foram injetados 10 microlitros por amostra. A velocidade era de $6 \mathrm{~mm} \mathrm{~min}^{-1}$. As misturas-padrões de calibração foram compostas pelos ácidos orgânicos alifáticos, não-voláteis, oxálico, malônico, succínico, málico, tartárico, fumárico, oxaloacético, cítrico e lático, na concentração de $200 \mathrm{mg} \mathrm{L}^{-1}$. Os ácidos orgânicos foram quantitativamente identificados pela comparação dos tempos de retenção e das áreas dos picos da amostra, com os da série dos padrões do HPLC (Auguste, 1979).

Procedeu-se à análise da variância, utilizando-se o seguinte modelo estatístico, para a avaliação dos efeito dos tratamentos no crescimento radicular e nos teores dos ácidos orgânicos:

Yijk $=\mu+B i+A j+C k+A C j k+\operatorname{erro}(i, j, k)$, onde: $\mathrm{B}=$ blocos $(\mathrm{i}=1,2,3) ; \mathrm{A}=$ concentração de $\mathrm{Al}$ $(\mathrm{j}=1,2) ; \mathrm{C}=$ cultivares $(\mathrm{k}=1,2,3,4)$. Na análise do $\mathrm{pH}$ da solução, foi incluído, no modelo (1), o fator $\mathrm{D}=$ dias $(1=1,2, \ldots, 9)$, com a restrição à casualização imposta por esse fator. Utilizou-se o teste Tukey $(\mathrm{P}<0,05)$, para a comparação das médias dos tratamentos que apresentavam diferenças $(\mathrm{P}<0,05)$ na análise da variância.

\section{Resultados e Discussão}

O incremento do comprimento da raiz primária do grupo das cultivares de soja sensíveis foi drasticamente afetado pelo Al, equivalendo a aproximadamente um quinto do crescimento ocorrido na ausência desse elemento (interação cultivar vs. Al) (Tabela 1). Essa redução foi, entretanto, muito menor entre as cultivares do grupo tolerante, chegando a não ser significativa $(\mathrm{P}<0,05)$ no FT-6. Na ausência de mecanismos de tolerância, essa ação tóxica do $\mathrm{Al}$ decorre do efeito inibidor no crescimento das raízes (expansão celular), que tem a plasticidade da parede celular afetada (Kochian, 1995).

Ocorreu maior decréscimo do $\mathrm{pH}$ da solução nutritiva com o tempo das plântulas de soja na solução sem $\mathrm{Al}$, na comparação com a solução com $\mathrm{Al}$ (interação Al vs. tempo) (Tabela 2). Como a acidificação do meio externo às raízes decorre da liberação de íons hidrogênio $\left(\mathrm{H}^{+}\right)$no processo de absorção de cátions, neste caso, do $\mathrm{Ca}$ (único cátion presente), deve ter ocorrido uma inibição de sua absorção pelo alumínio. As eventuais diferenças do $\mathrm{pH}$ da solução entre as cultivares na presença do Al não correspondem a uma possível imobilização desse elemento em forma precipitada, que requer $\mathrm{pH}$ maior do que 5,0 (Miyasaka et al., 1989), especialmente se forem considerados os valores correspondentes às cultivares FT-1 e FT-6, do grupo tolerante ao alumínio. As pequenas variações ocorridas estão, provavelmente, mais relacionadas ao não controle de temperatura da solução (Camargo, 1983). Então, os resultados do presente trabalho fazem supor que o 
mecanismo de tolerância das cultivares ao Al não é causado pela liberação de aníons $\mathrm{OH}^{-}$ou bases Brönsted-Lowry $\mathrm{HCO}_{3}^{-}$, ou $\mathrm{RCOO}^{-}$pelas raízes ao meio externo (Kirby, 1968; Foy et al., 1969); essa afirmação fica restrita, no entanto, às condições experimentais do presente estudo, que diferem das con-

Tabela 1. Incremento médio da raiz primária de cultivares de soja em diferentes concentrações de alumínio $^{(1)}$.

\begin{tabular}{lllr}
\hline Cultivar & Reação ao alumínio & \multicolumn{2}{c}{$\begin{array}{c}\text { Concentração de alumínio } \\
\left(\mathrm{mg} \mathrm{L}^{-1}\right)\end{array}$} \\
\cline { 3 - 4 } & & 0,0 & 0,2 \\
\hline FT-1 & Tolerante & $21,1 \mathrm{cA}$ & $14,9 \mathrm{bB}$ \\
FT-6 & Tolerante & $24,8 \mathrm{ab} \mathrm{A}$ & $21,4 \mathrm{aA}$ \\
IAC-13 & Sensível & $22,6 \mathrm{bcA}$ & $3,2 \mathrm{cB}$ \\
Paraná & Sensível & $28,6 \mathrm{aA}$ & $7,1 \mathrm{cB}$ \\
\hline
\end{tabular}

(1)Médias seguidas de mesmas letras, minúsculas nas colunas e maiúsculas nas linhas, não diferem entre si pelo teste de Tukey a $5 \%$ de probabilidade. dições do meio rizosférico das plantas que se desenvolvem no solo.

Foram analisados cinco ácidos orgânicos não-voláteis na matéria fresca do extrato de raízes das cultivares de soja (Tabela 3). A eluição completa da amostra na coluna ocorreu em 10 minutos e, a exemplo do que ocorreu com Lee \& Foy (1986) e Miyasaka et al. (1991), o pico inicial do solvente ocorreu aos quatro minutos, e foi identificado como um composto não-polar, que não interfere na determinação dos ácidos orgânicos.

Os conteúdos de ácidos orgânicos na ausência de Al foram, em ordem decrescente, cítrico, lático, succínico, oxálico e málico, com 51\%, 21\%, 19\%, $6 \%$ e $3 \%$, respectivamente; e na presença de $\mathrm{Al}$, foram, na mesma ordem, com $62 \%, 13 \%, 14 \%, 10 \%$, e $1 \%$, respectivamente.

Tabela 2. Valores médios diários de pH na solução em função de diferentes concentrações de alumínio e cultivares de $\operatorname{soja}^{(1)}$.

\begin{tabular}{|c|c|c|c|c|}
\hline \multirow[t]{2}{*}{ Dia } & \multicolumn{2}{|c|}{ Tolerante } & \multicolumn{2}{|c|}{ Sensível } \\
\hline & FT-1 & FT-6 & Paraná & IAC-13 \\
\hline & \multicolumn{4}{|c|}{$0,0 \mathrm{mg} \mathrm{L}^{-1}$ de alumínio } \\
\hline 1 & $4,77 \mathrm{aA} a$ & $4,79 \mathrm{aA} a$ & $4,79 \mathrm{aA} a$ & $4,78 \mathrm{aA} a$ \\
\hline 2 & $4,75 \mathrm{aA} a$ & $4,75 \mathrm{aA} a$ & $4,75 \mathrm{aA} b$ & $4,69 \mathrm{abA} b$ \\
\hline 3 & $4,67 \mathrm{abA} b$ & $4,66 \mathrm{abA} a$ & $4,74 \mathrm{abA} b$ & $4,67 \mathrm{abA} b$ \\
\hline 4 & $4,56 \mathrm{bcA} b$ & $4,56 \mathrm{bcA} b$ & $4,66 \mathrm{abA} b$ & $4,60 \mathrm{bcA} b$ \\
\hline 5 & $4,45 \mathrm{cdA} b$ & $4,45 \mathrm{cdA} b$ & $4,57 \mathrm{bcA} b$ & $4,53 \mathrm{bcdA} b$ \\
\hline 6 & $4,36 \mathrm{de} A b$ & $4,36 \mathrm{deA} b$ & $4,47 \mathrm{cdA} b$ & $4,44 \mathrm{cdeA} b$ \\
\hline 7 & $4,29 \mathrm{de} \mathrm{AB} b$ & $4,27 \mathrm{efB} b$ & $4,42 \mathrm{cdA} b$ & $4,39 \mathrm{de} \mathrm{AB} b$ \\
\hline 8 & $4,19 \mathrm{efAB} b$ & $4,14 \mathrm{fgB} b$ & $4,31 \mathrm{de} \mathrm{A} b$ & $4,29 \mathrm{efA} b$ \\
\hline \multirow[t]{2}{*}{9} & $4,09 \mathrm{fAB} b$ & $4,02 \mathrm{gB} b$ & $4,22 \mathrm{eA} b$ & $4,19 \mathrm{fA} b$ \\
\hline & \multicolumn{4}{|c|}{$0,2 \mathrm{mg} \mathrm{L}^{-1}$ de alumínio } \\
\hline 1 & $4,73 \mathrm{abA} a$ & $4,78 \mathrm{abcA} a$ & $4,78 \mathrm{abA} a$ & $4,74 \mathrm{abA} a$ \\
\hline 2 & $4,80 \mathrm{abA} a$ & $4,61 \mathrm{cB} b$ & $4,87 \mathrm{abAa}$ & $4,83 \mathrm{abA} a$ \\
\hline 3 & $4,88 \mathrm{aAB} a$ & $4,74 \mathrm{abcA} a$ & $4,95 \mathrm{aAa}$ & $4,89 \mathrm{aA} a$ \\
\hline 4 & $4,84 \mathrm{abA} a$ & $4,87 \mathrm{aA} a$ & $4,89 \mathrm{abA} a$ & $4,84 \mathrm{abA} a$ \\
\hline 5 & $4,80 \mathrm{abA} a$ & $4,82 \mathrm{abA} a$ & $4,84 \mathrm{abA} a$ & 4,79abAa \\
\hline 6 & 4,81abAa & 4,84abAa & $4,86 \mathrm{abA} a$ & $4,81 \mathrm{abA} a$ \\
\hline 7 & $4,82 \mathrm{abA} a$ & $4,82 \mathrm{abA} a$ & $4,87 \mathrm{abAa}$ & $4,81 \mathrm{abA} a$ \\
\hline 8 & 4,74abAa & $4,76 \mathrm{abcA} a$ & $4,78 \mathrm{abA} a$ & $4,74 \mathrm{abA} a$ \\
\hline 9 & $4,70 \mathrm{bA} a$ & $4,68 \mathrm{bcA} a$ & $4,75 \mathrm{bAa}$ & $4,71 \mathrm{bA} a$ \\
\hline
\end{tabular}

(1)Valores seguidos de mesma letra não diferem entre si pelo teste de Tukey a $5 \%$ de probabilidade: fixando nível vs. cultivar, comparando dias, letras minúsculas na coluna, em estilo normal; fixando nível vs. dia, comparando cultivares, letras maiúsculas na linha; fixando dia vs. cultivar, comparando níveis, letras minúsculas na coluna, em itálico. 
$\mathrm{Na}$ ausência de $\mathrm{Al}$, o grupo tolerante acumulou $54 \%$ do total dos ácidos orgânicos identificados, e o grupo sensível, 46\%. Lee \& Foy (1986) também encontraram, em extratos de raízes de feijão, maiores acúmulos de ácidos na cultivar tolerante, com $52 \%$, contra $48 \%$ na cultivar sensível. Cambraia et al. (1983) também encontraram maiores acúmulos de ácidos na cultivar tolerante de sorgo, com $69 \%$, contra $31 \%$, na cultivar sensível. Na solução com $\mathrm{Al}$, houve um decréscimo na produção de ácidos orgânicos em relação à solução sem $\mathrm{Al}$; este decréscimo foi maior no grupo das cultivares sensíveis (interação cultivar vs Al). O decréscimo no grupo tolerante foi de $31 \%$, e no sensível, de $46 \%$. Klimashevskii \& Chernysheva (1980) também constataram decréscimo nas concentrações de ácidos orgânicos em ervilha, milho, cevada e trigo de primavera, quando submetidos a níveis crescentes de $\mathrm{Al}$, sendo os mesmos, entretanto, independentes do grupo de tolerância.

Individualmente, o ácido cítrico apresentou o valor mais elevado, tanto na solução sem $\mathrm{Al}$, como na solução com $\mathrm{Al}$, indicando ser uma característica da espécie (Popp \& Kinzel, 1981). Na solução com $0,2 \mathrm{mg} \mathrm{L}^{-1}$ de Al, a cultivar FT-6, do grupo tolerante manteve o mesmo acúmulo de ácido cítrico verificado na solução sem alumínio. A outra cultivar do grupo tolerante (FT-1) apresentou um decréscimo de $23 \%$. Entretanto, a cultivar Paraná, do grupo sensível, que na solução sem Al acumulou a mesma quantidade de ácido das cultivares tolerantes, apresentou um decréscimo de $52 \%$. A outra cultivar, IAC-13, que já apresentava baixa quantidade de ácido cítrico na solução sem Al, baixou mais ainda, na presença de alumínio.

A manutenção do conteúdo de ácido cítrico, sob pressão do nível tóxico de Al, ocorrida em FT-6, ou a diminuição (23\%) ocorrida em FT-1, ambas tolerantes, pressupõe que existe, entre elas, genes diferentes deste caráter (Neenan, 1960), pois o FT-1 é uma seleção na cultivar Sant'Ana, e o FT-6 provém de cruzamento de FT9510 x Prata, que são genitores sem parentesco.

O grupo tolerante acumulou $64 \%$ do total como ácido cítrico, no nível de $0,2 \mathrm{mg} \mathrm{L}^{-1}$ de $\mathrm{Al}$, contra $36 \%$ do grupo sensível, permitindo inferir que o ácido cítrico estaria ligado ao processo de tolerância ao alumínio. Esses resultados estão de acordo com a relação entre os maiores conteúdos de ácidos orgânicos e cultivares tolerantes em diferentes níveis de Al, encontrada por Bartlett \& Riego (1972).

$\mathrm{O}$ ácido cítrico tem sido indicado como o mais ativo complexante e desintoxicante do Al (Bartlett \& Riego, 1972). A sua ocorrência em concentrações maiores e o maior desenvolvimento das raízes nas cultivares tolerantes de soja levam à conclusão de que esteja envolvido no processo de complexação e desintoxicação. As cultivares sensíveis apresentaram níveis menores de ácido cítrico e sistemas de raízes menores e atrofiados (Tabela 1), sendo menos protegidos dos efeitos danosos causados pelo alumínio.

A possibilidade de que o ácido cítrico esteja envolvido na complexação do Al internamente, nas

Tabela 3. Teores médios de ácidos orgânicos no sistema de raízes de cultivares de soja em função de diferentes níveis de alumínio ${ }^{(1)}$

\begin{tabular}{lccccccc}
\hline Cultivar & Reação ao Al & Ácido cítrico & Ácido lático & Ácido succínico & Ácido oxálico & Ácido málico & Total \\
\hline & & & \multicolumn{5}{c}{$0,0 \mathrm{mg} \mathrm{L}^{-1}$ de alumínio } \\
FT-1 & Tolerante & $38,54 \mathrm{a}$ & $17,04 \mathrm{a}$ & $14,72 \mathrm{ab}$ & $5,06 \mathrm{a}$ & $1,92 \mathrm{a}$ & $77,28 \mathrm{a}$ \\
FT-6 & Tolerante & $41,98 \mathrm{a}$ & $18,28 \mathrm{a}$ & $12,66 \mathrm{~b}$ & $6,10 \mathrm{a}$ & $0,99 \mathrm{a}$ & $80,01 \mathrm{a}$ \\
Paraná & Sensível & $38,76 \mathrm{a}$ & $17,02 \mathrm{a}$ & $15,30 \mathrm{a}$ & $3,26 \mathrm{~b}$ & $2,40 \mathrm{a}$ & $76,74 \mathrm{a}$ \\
IAC-13 & Sensível & $27,69 \mathrm{~b}$ & $9,86 \mathrm{~b}$ & $12,93 \mathrm{ab}$ & $2,62 \mathrm{~b}$ & $2,10 \mathrm{a}$ & $55,20 \mathrm{~b}$ \\
\hline & & & & $0,2 \mathrm{mg} \mathrm{L}^{-1}$ de alumínio & & \\
FT-1 & Tolerante & $30,00 \mathrm{~b}$ & $9,59 \mathrm{a}$ & $4,38 \mathrm{~b}$ & $3,42 \mathrm{~b}$ & $0,20 \mathrm{a}$ \\
FT-6 & Tolerante & $41,13 \mathrm{a}$ & $5,31 \mathrm{a}$ & $9,96 \mathrm{a}$ & $4,67 \mathrm{ab}$ & $0,21 \mathrm{a}$ & \\
Paraná & Sensível & $18,56 \mathrm{c}$ & $3,88 \mathrm{a}$ & $5,88 \mathrm{~b}$ & $3,96 \mathrm{ab}$ & $0,22 \mathrm{a}$ & $32,59 \mathrm{ab}$ \\
IAC-13 & Sensível & $21,76 \mathrm{bc}$ & $5,68 \mathrm{a}$ & $5,07 \mathrm{~b}$ & $5,58 \mathrm{a}$ & $0,40 \mathrm{a}$ & $38,40 \mathrm{bc}$ \\
\hline
\end{tabular}

${ }^{(1)}$ Dentro do mesmo nível de $\mathrm{Al}$, valores médios seguidos de mesma letra na coluna não diferem entre si pelo teste de Tukey a $5 \%$ de probabilidade 
raízes, é real. A sua eficiência é maior do que a dos outros ácidos, em razão de ter os grupos funcionais de hidroxilas e carboxilas (Struthers \& Sieling, 1950) ligados a dois carbonos adjacentes, e essa posição favorece a formação de estruturas estáveis com ligações cíclicas com o Al (Huang \& Violante, 1986; Hue et al., 1986).

Além do ácido cítrico, foram identificados outros ácidos, como o lático e o málico, não existindo diferença $(\mathrm{P}>0,05)$ entre as cultivares nos dois grupos (Tabela 3). Esses ácidos não são tão bons complexantes, e são identificados como de fraca desintoxicação (Hue et al., 1986). O succínico foi outro ácido do ciclo de Krebs identificado. O grupo tolerante acumulou $14 \%$ mais ácido succínico do que o grupo sensível, na solução com alumínio. No entanto, o ácido succínico é classificado como de fraca desintoxicação (Hue et al., 1986). O ácido oxálico, também intermediário do ciclo de Krebs, não diferiu em conteúdo, tanto entre as cultivares sensíveis como nas tolerantes.

Assim, a tolerância da soja ao Al pode ter a maior expressão na quantidade de ácido cítrico produzida pelas cultivares. Os resultados evidenciam a presença de um mecanismo interno de complexação do $\mathrm{Al}$ é ativado principalmente pelas diferenças de conteúdos de ácido cítrico, e pela observação de que as raízes das cultivares tolerantes continuam a se desenvolver, ao contrário do que ocorre nas cultivares sensíveis.

\section{Conclusões}

1. As cultivares de soja tolerantes ao $\mathrm{Al}$ apresentam maior crescimento da raiz primária do que as cultivares sensíveis na presença do $\mathrm{Al}$, e esta característica é confiável na seleção de genótipos de soja tolerantes e sensíveis.

2. A presença de $\mathrm{Al}$ diminui o conteúdo de ácidos orgânicos não-voláteis no sistema radicular; principalmente nas cultivares sensíveis.

3. As cultivares tolerantes ao $\mathrm{Al}$ podem ser diferenciadas das sensíveis pelo maior acúmulo de ácido cítrico.

\section{Referências}

AUGUSTE, M. H. Application de la chromatographie en phase liquide à haute pression à l'analiyse des moûts et des vins. Bordeaux: Université de Bordeaux II, 1979. $135 \mathrm{f}$. These de Docteur.

BARTLETT, R. J.; RIEGO, D. C. Effect of chelation on the toxicity of aluminum. Plant and Soil, Dordrecht, v. 37, p. 419-423, 1972.

CAMARGO, C. E. O. Efeito da temperatura da solução nutritiva na tolerância ao alumínio de cultivares de trigo. Bragantia, Campinas, v. 42, p. 51-63, 1983.

CAMBRAIA, J.; GALVANI, F. R.; ESTEVÃO, M. M.; SANTANA, R. Effects of aluminum on organic acid, sugar and amino acid composition on the root system of sorghum (Sorghum bicolor L. Moench). Journal of Plant Nutrition, New York, v. 6, p. 313-322, 1983.

DELHAIZE, E.; RYAN, P. R.; RANDALL, P. J. Aluminum tolerance in wheat (Triticum aestivum L.): II. Aluminum-stimulated excretion of malic acid from root apices. Plant Physiology, Rockville, v. 103, p. 695-702, 1993.

FOY, C. D. Plant adaptation to acid aluminum-toxic soils. Communications in Soil Science and Plant Analysis, New York, v. 19, p. 959-987, 1988.

FOY, C. D.; FLEMING, A. L.; ARMIGER, W. H. Aluminum tolerance of soybean varieties in relation to calcium nutrition. Agronomy Journal, Madison, v. 74, p. $687-690,1969$.

HELYAR, K. R. Effects of aluminum and manganese toxicities on legume growth. In: ANDREW. C. S.; KAMPRATH, E. J. (Ed.). Mineral nutrition of legumes in tropical an subtropical soils. Melbourne: CSIRO, 1987. p. 207-231.

HUANG, P. M.; VIOLANTE, A. Influence of organic acids on crystallization and surface properties of precipitation products of aluminum. In: HUANG, P. M.; SCHNITZER, M. (Ed.). Interactions of soil minerals with natural organic and microbes. Madison: Soil Science of America, 1986. p. 159-221.

HUE, N. V.; CRADDOCK, G. R.; ADAMS, F. Effect of organic acids on aluminum toxicity in subsoils. Soil Science Society of America Proceedings, Madison, v. 5, p. 28-34, 1986.

KIRBY, E. A. Influence of ammonium and nitrate nutrition on the cation-anion balance and nitrogen and carbohydrate metabolism of white mustard plants grown in dilute nutrient solution. Soil Science, Baltimore, v. 105, p. 133 $141,1968$. 
KLIMASHEVSKII, E. L.; CHERNYSHEVA, N. F. Content of organic, acids and physiologically active compounds in plants differing in their susceptibility to the toxicity of $\mathrm{Al}^{3+}$. Soviet Agricultural Sciences, Washington, v. 2 , p. 5-8, 1980

KOCHIAN, L. V. Cellular mechanisms of aluminum toxicity and resistance in plants. Annual Review of Plant Physiology and Plant Molecular Biology, Palo Alto, v. 4, p. 237-260, 1995.

KURKDJIAN, A.; GUERN, J. Intracellular $\mathrm{pH}$ : measurement and importance in cell activity. Annual Review of Plant Physiology and Plant Molecular Biology, Palo Alto, v. 40, p. 271-303, 1989.

LEE, E. H.; FOY, C. D. Aluminum tolerances of two snapbean cultivars related to organic acid content evaluated by high performance liquid chromatography. Journal of Plant Nutrition, New York, v. 9, p. 1481-1498, 1986.

McALISTER, D. F.; KROBER, O. A. Translocation of food reserves from soybean cotyledons and their influence on the development of the plant. Plant Physiology, Rockville, v. 26, p. 525-528, 1951.

MATSUMOTO, H.; HIRASAWA, F.; MORIMUTA, S.; TAKAHASHI, E. Localization of aluminum in tea leaves. Plant and Cell Physiology, Kyoto, v. 17, p. 890-895, 1976.

MENOSSO, O. G.; COSTA, J. A.; ANGHINONI, I.; BOHNEN, H. Tolerância de genótipos de soja em solução nutritiva diluída. Pesquisa Agropecuária Brasileira, Brasília, v. 35, n. 11, p. 2157-2166, 2000.

MIYASAKA, S. C.; BUTA, J. G.; HOWELL, R. K.; FOY, C. D. Mechanism of aluminum tolerance in snapbeans: root exudation of citric acid. Plant Physiology, Rockville, v. 96, p. $737-743,1991$.

MIYASAKA, S. C.; KOCHIAN, L. V.; SHAFF, J. E.; FOY, C. D. Mechanisms of aluminum tolerance in wheat: an investigation of genotypic differences in rhizosphere $\mathrm{pH}$,
$\mathrm{K}^{+}$, and $\mathrm{H}^{+}$transport, and root-cell membrane potentials. Plant Physiology, Rockville, v. 91, p. 1188-1196, 1989.

MIYASAWA, M.; CHIERICE, G. O.; PAVAN, M. A. Amenização da toxicidade de alumínio à raízes do trigo pela complexação com ácidos orgânicos. Revista Brasileira de Ciência do Solo, Campinas, v. 16, p. 209-215, 1992.

MUNNS, D. N. Soil acidity and growth of legume: II. Reactions of aluminum and phosphate in solution and effects of aluminum, phosphate, calcium and $\mathrm{pH}$ on Medicago sativa and Trifolium subterraneum L. in solution culture. Australian Journal of Agricultural Research, Collingwood, v. 16, p. 743-752, 1965.

NEENAN, M. The effects of soil acidity on the growth of cereals with particular reference to the differential reaction of varieties thereto. Plant and Soil, Dordrecht, v. 12, p. $324-338,1960$.

NEWMANN, D. W. Instrumental methods of experimental biology. New York: MacMillan, 1964. p. 126-131.

POPP, M.; KINZEL, H. Changes in the organic acid content of some cultivated plants induced by mineral ion deficiency. Journal of Experimental Botany, Oxford, v. 32 , p. $1-8,1981$.

STRUTHERS, P. H.; SIELING, D. H. Effect of organic anions on phosphate precipitation by iron and aluminum as influenced by pH. Soil Science, Baltimore, v. 69, p. 205213,1950

SUHAYDA, C. G.; HAUG, A. Citrate chelation as a potential mechanism against aluminum toxicity in cells: the role of calmodulin. Canadian Journal of Biochemistry and Cell Biology, Ottawa, v. 63, p. 11671175, 1985.

TAYLOR, G. J. The physiology of aluminum tolerance in higher plants. Communications in Soil Science and Plant Analysis, New York, v. 19, p. 1179-1194, 1988. 